\title{
Impact of Unsafe Abortion: A Case Report
}

\author{
Soni M, Meena D, Vyas J, Khajotiya S \\ Department of Obs/Gyn, SP Medical College and PBM Group of Hospitals, Bikaner-334001, Rajasthan, India
}

Legalization of abortion is a necessary but insufficient step towards improving women's health, if it is not supported by a strong back-up of skilled providers, adequate facilities and easy access. We report a case of a 20 -year old female, who presented with uterine, vaginal and rectal perforation with macerated fetus in the abdominal cavity with severe sepsis after an attempted unsafe abortion.

Keywords: Criminal abortion, unsafe abortion

\section{INTRODUCTION}

Legalization of abortion is a necessity but insufficient step towards improving women's health, in the absence of skilled providers, adequate facilities and easy access, when the promise of safe legal abortion will remain unfulfilled, as in the case being reported a young female who risked her life in an attempt for criminal abortion. The procedure was complicated by uterine, vaginal and rectal injuries and severe sepsis with macerated fetus lying in abdominal cavity.

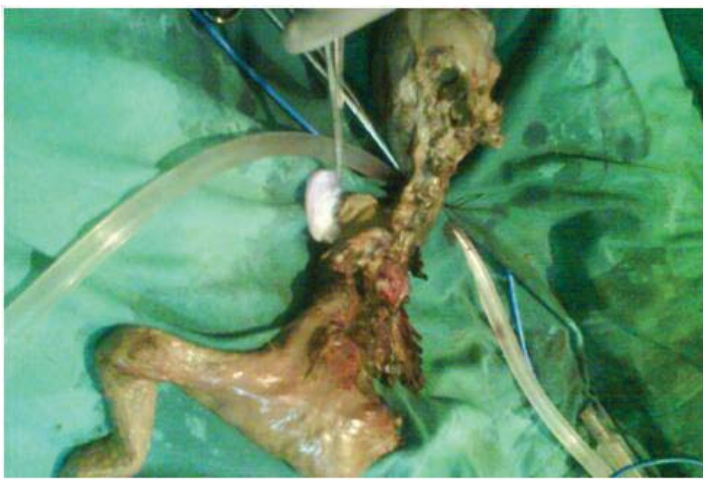

Figure 1. Macerated and decomposed fetus

\section{CASE}

A 20 year old unmarried female was admitted at P.B.M. Hospital, Bikaner, with chief complaint of foul smelling discharge per vagina. She gave false history of evacuation of missed abortion 15 days back. This was actually an attempted criminal abortion by an unskilled attendant. The patient had abdominal distension and foul smelling discharge per vagina since then. On examination, her general condition was poor. She had tachycardia, high grade fever and a dehydrated look. There was abdominal distension with absent bowel sounds. On per vagina and per rectum examination, there was rent in posterior fornix

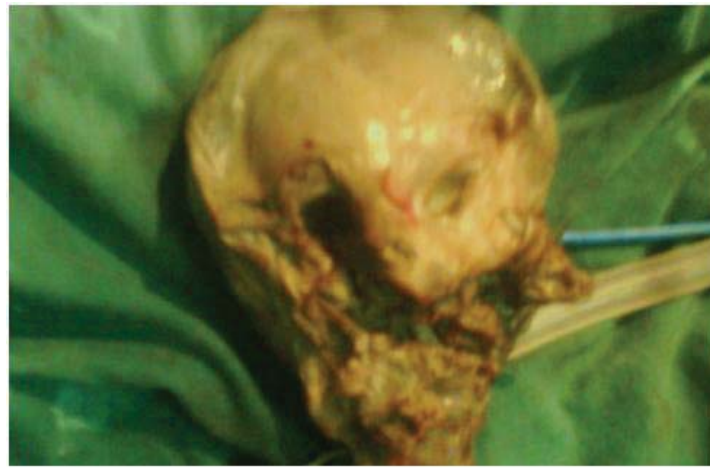

Figure 2. Facial anatomy of the macerated fetus

\section{CORRESPONDENCE}

Dr. Monica Soni, MS

Department of Obstetrics and Gynaecology

SP Medical College and PBM Group of Hospitals

IV-E-477-78, J.N.Vyas Colony

Bikaner-334003, Rajasthan, India

Ph.09982350350

Email: drmonikasoni3008@gmail.com 


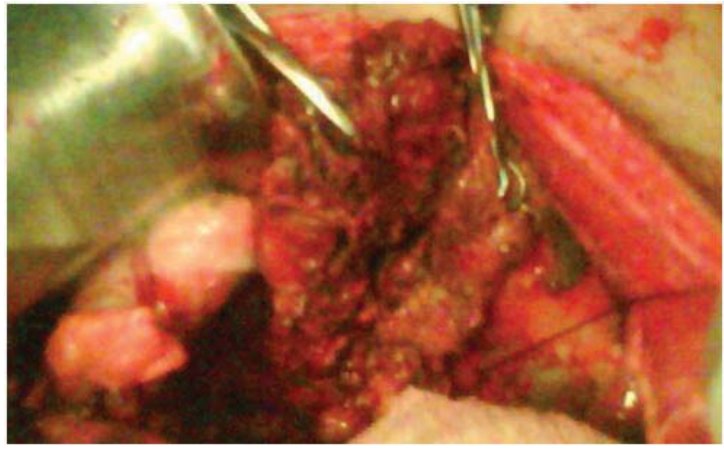

Figure 3. Torn posterior wall of the uterus

and posterior wall of vagina, extending upwards into the body of uterus. Anterior wall of rectum had a large rent involving full thickness of the rectal wall. Discharge was extremely foul smelling and offensive. Laparotomy was decided. On laparotomy, the abdominal cavity was full of purulent discharge with a highly offensive odor. There was a macerated, decomposed fetus of around 26 weeks lying in the abdominal cavity. Placenta could not be made out. There was a large rent in the posterior wall of uterus involving the posterior fornix and posterior wall of vagina. Both ovaries and fallopian tubes were inflamed and covered with purulent exudates. There was a large full thickness tear involving the anterior and lateral walls of rectum. Rectal walls were gangrenous and sloughing. Transection of colon was done at recto-sigmoid junction. Colostomy was done. Rent in the uterus was repaired. Vaginal rent was repaired partially. Debridement of sloughed tissues was done. Peritoneal lavage was done. Patient remained stable during the procedure.

Complications from unsafe abortions account for a large proportion of hospital admissions for gynecological services in developing countries. The WHO estimates that one in eight pregnancy- related deaths result from unsafe abortions. ${ }^{1}$
Every year, worldwide, about 42 million women with unintended pregnancies choose abortion, and nearly half of these procedures, 20 million, are unsafe..$^{2,3}$ Some 68,000 to 70,000 women die of unsafe abortion annually making it one of the leading causes of maternal mortality(13\%). ${ }^{2,3}$ Of the women who survive unsafe abortion, 5 million will suffer long-term health complications. ${ }^{2}$

Both of the primary methods of preventing unsafe abortion - less restrictive abortion laws and greater contraceptive use - face social, religious and political obstacles, particularly in developing nations, where most unsafe abortions (97\%) occur. ${ }^{3}$ Even when these obstacles are overcome, women and healthcare providers need to be educated about contraception and the availability of legal and safe abortion, and women need better access to safe abortion and post-abortion services. ${ }^{3}$

\section{CONCLUSIONS}

Desperate women, facing the social stigma of unintended pregnancy is expected to continue riskisking their lives by undergoing unsafe abortions not knowing the existence of safe abortion service (SAS) provision. Therefore, public awareness must be created against harmful practices of criminal abortions alerting them to access the right facility.

\section{REFERENCES}

1. Singh S. Hospital admissions resulting from unsafe abortions : estimates from 13 developing countries. Lancet.2006; 368(9550):1887-92.

2. Haddad LB, Nour NM. Unsafe abortion : Unnecessary maternal mortality. Rev Obstet Gynecol.2009;2(2):122-6.

3. Shah I, Ahman E. Unsafe abortion: Global and regional incidence, trends, consequences, and challenges. J Obstet Gynecol Can.2009; 31(12):1149-58. 